\title{
Counting the books while the library burns: why conservation monitoring programs need a plan for action
}

\author{
David B Lindenmayer ${ }^{1 *}$, Maxine P Piggott ${ }^{1}$, and Brendan A Wintle ${ }^{2}$
}

Conservation monitoring programs are critical for identifying many elements of species ecology and for detecting changes in populations. However, without articulating how monitoring information will trigger relevant conservation actions, programs that monitor species until they become extinct are at odds with the primary goal of conservation: avoiding biodiversity loss. Here, we outline cases in which species were monitored until they suffered local, regional, or global extinction in the absence of a preplanned intervention program, and contend that conservation monitoring programs should be embedded within a management plan and characterized by vital attributes to ensure their effectiveness. These attributes include: (1) explicit articulation of how monitoring information will inform conservation actions, (2) transparent specification of trigger points within monitoring programs at which strategic interventions will be implemented, and (3) rigorous quantification of the ability to achieve early detection of change.

Front Ecol Environ 2013; 11(10): 549-555, doi:10.1890/120220 (published online 11 Nov 2013)

$\mathrm{T}_{\mathrm{p}}^{\mathrm{h}} \mathrm{c}$ he continuing loss of biodiversity is a serious global problem (Butchart et al. 2010). Of the 63837 species assessed worldwide using the International Union for Conservation of Nature (IUCN) Red List criteria, 865 are extinct or extinct in the wild and 19817 are listed as critically endangered, endangered, or vulnerable to extinction (IUCN 2012). Since the start of the 21st century alone, at least 10 species of vertebrates are known to have gone extinct, although this is likely to be a substantial underestimate. The only way to know whether populations of a species are declining is by monitoring them, thus

\section{In a nutshell:}

- Monitoring is a critical part of effective species conservation, but many species are being monitored until they go extinct

- Management intervention should be triggered when it becomes apparent that a monitored species is in decline

- Most conservation monitoring programs lack preplanned interventions and a clear statement about how the information derived from monitoring will help to conserve the species

- Conservation monitoring programs and management plans should identify trigger points for prespecified management interventions

${ }^{1}$ Fenner School of Environment and Society; Australian Research Council Centre of Excellence for Environmental Decisions; and National Environmental Research Program, The Australian National University, Canberra, Australia *(david.lindenmayer@ anu.edu.au); ${ }^{2}$ School of Botany; Australian Research Council Centre of Excellence for Environmental Decisions; and National Environmental Research Program, University of Melbourne, Melbourne, Australia making monitoring an essential conservation activity.

There are a variety of reasons to monitor biodiversity, including learning about a species' ecology and population biology, reporting on the state of biodiversity, and estimating the state of (or detecting changes in) populations so that appropriate actions can be taken (Yoccoz et al. 2001). However, when a monitoring program is funded under the specific objective of conserving a species that has been identified as imperiled, it would seem reasonable to expect that the monitoring would, at the very least, aim to detect population changes that trigger specific and timely conservation actions, and/or clarify aspects of the species' ecology or population biology that are most immediately relevant to improving the effectiveness of conservation actions. Unfortunately, conservation monitoring programs commonly (1) track the state of a population without any plan for what will be done if a given change is observed or (2) collect information on the species' ecology or population biology that has no immediate relevance to decisions about the most appropriate course of action to prevent extinction. The end result may be that the decline and extinction of species is accurately recorded without any effective attempts at mitigation.

Monitoring a species until it becomes extinct is clearly not a conservation policy that would ever be earnestly proposed. Yet the conservation literature contains many examples of threatened or endangered species being monitored until they went locally, regionally, or globally extinct (WebTable 1). This unfortunate phenomenon may become more frequent in the future, given both the large number of imperiled species globally (IUCN 2012) and the prevalence of poorly designed and implemented biodiversity monitoring programs (Nichols and Williams 2006; Lindenmayer and Likens 2010) that lack a sound 

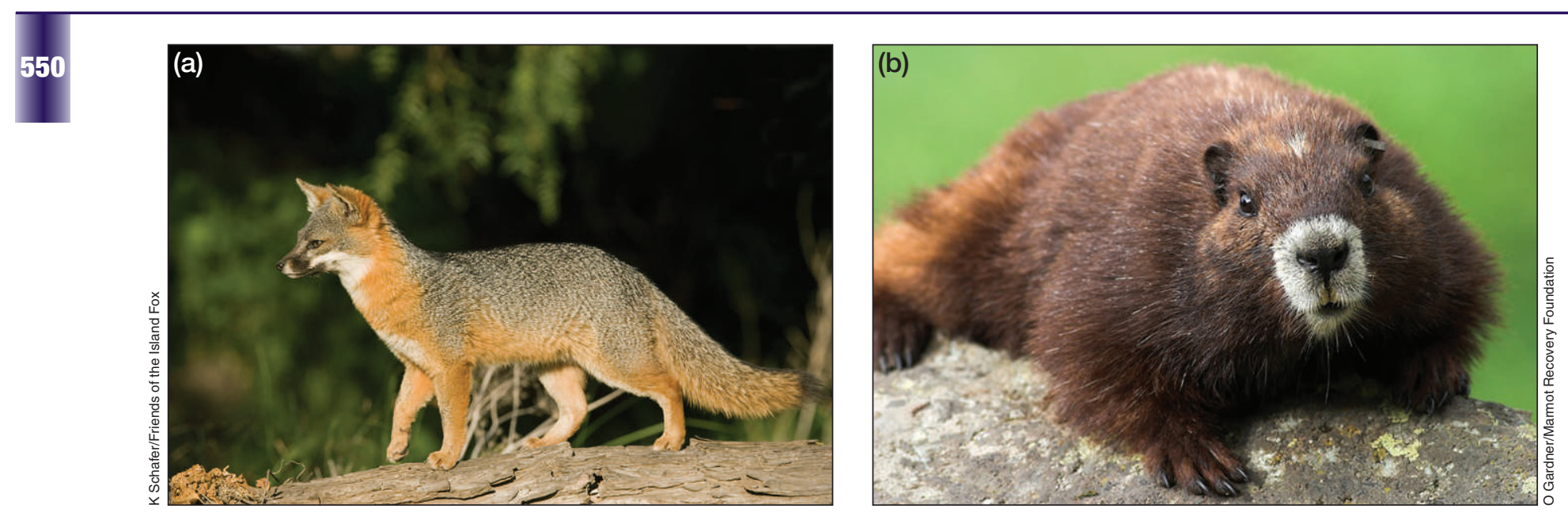

Figure 1. (a) Channel Island fox (Urocyon littoralis), a species for which there was a carefully structured recovery plan with triggers to instigate intervention, and (b) Vancouver Island marmot (Marmota vancouverensis), a species that suffered local and regional extinction while it was being monitored; see WebTable 1.

decision framework and fail to include thresholds of change that trigger conservation actions commensurate with the magnitude of the observed decline.

Here, we summarize cases in which species were monitored passively (ie without effective management intervention) until they became locally or even globally extinct (WebTable 1). On the basis of the compiled examples, we infer some of the reasons behind the failure to prevent extinctions. To further demonstrate manifestations of the symptoms associated with monitoring and management failure, we focus on the example of the greater glider (Petauroides volans), an Australian marsupial that was monitored until it became regionally extinct. We also present an overview of 191 threatened species recovery plans (WebTable 2) to explore the degree to which existing biodiversity monitoring and associated recovery programs are designed to activate changes in management early enough to provide a reasonable chance of avoiding extinction. Finally, we make five key recommendations aimed at improving conservation monitoring programs and decreasing the chances of species disappearing despite being monitored.

\section{Species that were monitored without management intervention until they went extinct}

After searching the published scientific literature and contacting colleagues (see Acknowledgements) for examples of species that suffered local, regional, or global extinction while being monitored, we identified 34 such cases (WebTable 1; Figure 1b). There are likely to be additional cases that were never formally reported or have only been described in non-peer-reviewed literature.

The cases highlighted in WebTable 1 cover a range of species in mostly western countries. Examples are dominated by mammals and amphibians, although several species of birds are also represented. Cases of reptiles, fish, and invertebrates were rare, although this may reflect a taxonomic bias in organisms that tend to be monitored and for which extinction risk assessments are undertaken.

The likely causes of decline in many of the examples appear to be relatively well known: for example, the West African black rhinoceros (Diceros bicornis longipes) through poaching, and the Bay checkerspot butterfly (Euphydryas editha bayensis) as a result of the loss of host plants through alien plant species invasion. However, the cause of extinction was unknown in 14 of the 34 examples, particularly among amphibian species. Eight of these case studies had management and/or conservation plans prior to extinction but in many instances these appear to have been implemented too late and were ineffective (eg Kihansi spray toad [Nectophrynoides asperginis], po'ouli [Melamprosops phaeosoma], Christmas Island pipistrelle [Pipistrellus murrayi]). Surprisingly, we rarely found documentation of attempts to secure a viable captive population or even a discussion as to why such action would be unlikely to succeed. Our literature search revealed that failure to strategically plan for action in response to monitoring data is an international phenomenon that includes many countries, including the US and Australia, with relatively high national investments in conservation management as well as strong communities of conservation practitioners.

\section{Cases of insufficient knowledge and unknown drivers of decline}

Examples listed in WebTable 1 and our case study below highlight instances where the drivers of decline and eventual extinction were unknown. There are at least two interrelated ways to address this problem. One method is to carefully weigh potential threatening processes and eliminate those that evidence and logic suggest are unimportant, leaving the remainder as likely factors underpinning decline. Analysis of the rapid loss of bird populations on the North Pacific island of Guam is a powerful illustration of this approach (Savidge 1987). Studies that quantify the specific driver or drivers of 

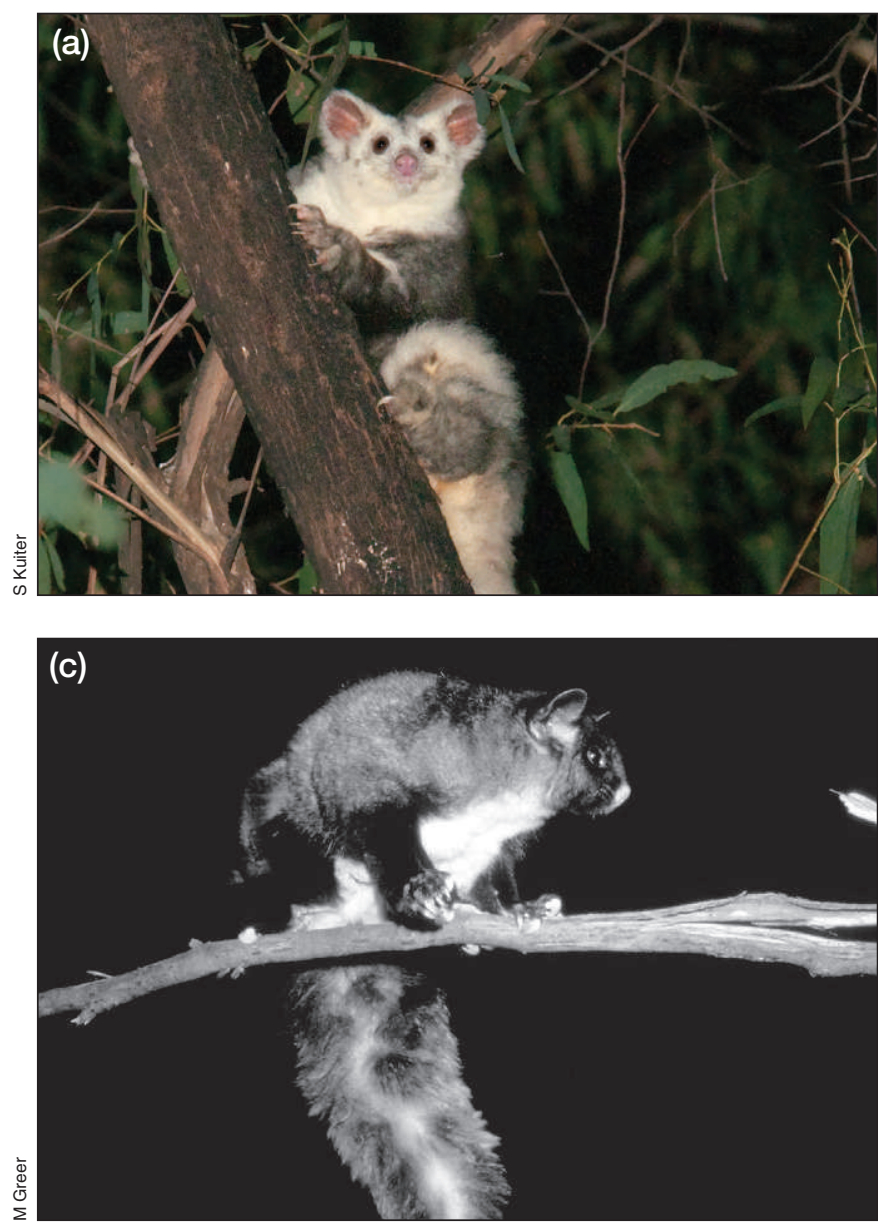

decline and analyze the benefits of mitigation options are central to managing declines (Caughley and Gunn 1996; Runge et al. 2011). An elegant example is the long-term work by Thomas et al. (2009) on threatened Maculinea spp butterflies in the UK. These authors showed that the larvae of these butterflies produce secretions that are consumed by a particular species of ant. These ants in turn protect the larvae from predation and even escort newly emerged adults from the ant nest to the surface. Thomas et al. (2009) demonstrated that ecosystem changes in vegetation structure triggered by subtle changes in grazing led to replacement of the host ants required by butterfly larvae by other ant species that were unsuitable hosts.

\section{A case study in which a species was monitored until it went extinct}

A biodiversity monitoring program has been in place since 2003 in the 6600-ha Booderee National Park in southern Australia. The program is based on 134 permanent field sites. Part of the work is focused on populations of nocturnal arboreal marsupials (Lindenmayer et al. 2008). One species, the greater glider (Figure 2a), was common at the beginning of the monitoring program in 2003. A substantial decline in the glider's population was apparent by 2005, and by 2007 no animals could be found. The species has remained unrecorded

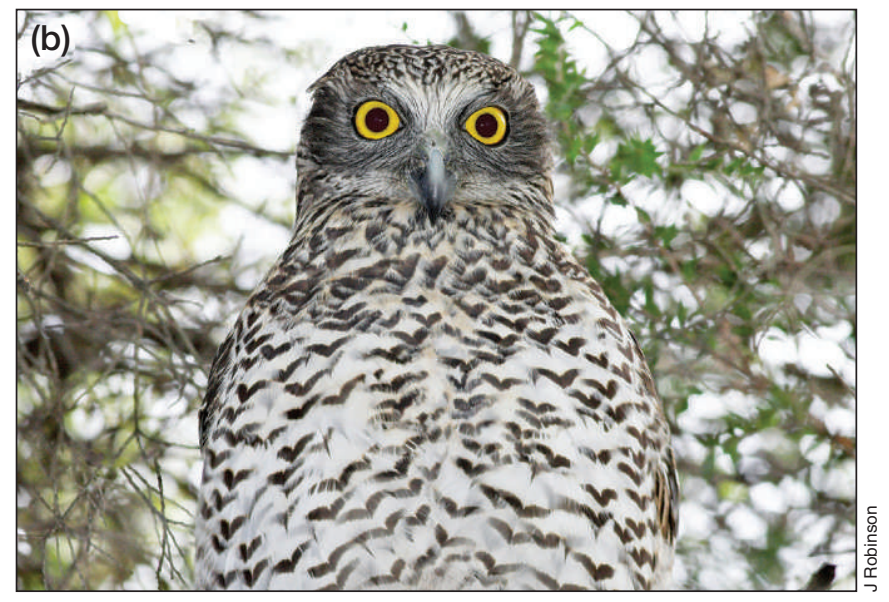

Figure 2. (a) Greater glider (Petauroides volans), (b) powerful owl (Ninox strenua), and (c) yellow-bellied glider (Petaurus australis).

in the park from 2008 to 2013, despite it being the most readily detected species of arboreal marsupial elsewhere in its range (Lindenmayer 2002).

The reasons for the population collapse of the greater glider remain unclear. It may be a side-effect of widespread feral predator control leading to either an increase in the population of large forest owls in Booderee with a subsequent increase in predation pressure on greater gliders (Dexter et al. 2012), and/or an increase in competition for hollows in large trees between gliders and larger arboreal marsupials, such as the common brushtail possum (Trichosurus vulpecula), that have been increasing in abundance after populations of the exotic red fox (Vulpes vulpes) were controlled (Lindenmayer et al. 2008).

Another species of arboreal marsupial, the yellow-bellied glider (Petaurus australis; Figure 2c), went extinct in Booderee in the late 1980s. The common ringtail possum (Pseudocheirus peregrinus) is exhibiting a population trajectory similar to that shown in Figure 3 for the greater glider; the former species occupied $71(\sim 50 \%)$ sites in 2003 but has been recorded at fewer than five of 134 ( 4\%) field monitoring sites since 2009 (Lindenmayer et al. unpublished data).

The original design of the biodiversity monitoring program at Booderee National Park did not include trigger points for management action, despite the past local extirpation of the yellow-bellied glider in the park. Although the more recent extinction of the greater glider raised concern among management staff and researchers, decisions about how the monitoring program and management practices might be altered have yet to be made. This may be due to a perceived lack of resources and practical options to address possible threats; for example, large predatory owls are also taxa of conservation concern and culling those owls is currently not a management option. Because none of these species are listed as nationally endangered, captive breeding is not considered to be an economically viable option for conservation of local genetic variation. 


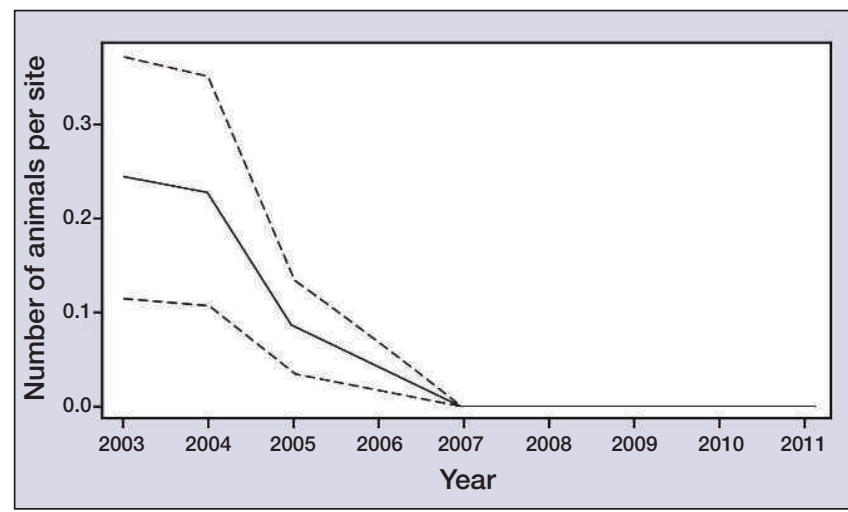

Figure 3. Per site abundance of the greater glider averaged across 134 permanent field sites within Booderee National Park in southeastern Australia (updated from Lindenmayer et al. 2011).

What might have been done differently in Booderee to have avoided the local extirpation of the greater glider? First, the monitoring program itself should have been modified using an "adaptive monitoring" approach (sensu Lindenmayer and Likens 2009) that would have increased the frequency of surveys from 1 to 3-4 annually, to confirm earlier that a substantial population decline was occurring. Second, a process of assessing the potential drivers of decline should have been instigated, with likely candidate factors distinguished from those that were implausible. These factors could then have been examined as part of adapting the existing monitoring design. Finally, the management plan (Director of National Parks 2011) could have been revised to include trigger points for action as soon as further evidence of decline was compiled; the inclusion of trigger points would have been appropriate given recent extinctions in Booderee National Park and the many species of conservation concern therein. These actions could have included, for example: (1) the capture, removal, and translocation of pairs of large owls - such as the powerful owl (Ninox strenua; Figure 2b) - from the reserve using such methods as playback calling and subsequent trapping (Soderquist et al. 2002), or (2) an experimental reintroduction of the greater glider using individuals captured from elsewhere in the region to test competing hypotheses about the decline being driven by greater numbers of large forest owls versus interspecific competition for tree hollows. A proposal to undertake such an experimental reintroduction program was developed in 2012 and estimated to cost approximately US $\$ 160000$, but the program has not taken place because of budget constraints and other conservation program priorities.

\section{The importance of monitoring and its links with adaptive management}

Many monitoring programs, including those aimed at conserving biodiversity, are poorly designed and/or fail (Lindenmayer and Likens 2010). Better designed monitoring programs must have trigger points to instigate action when a major decline in a population is observed. This is particularly important when several different species are disappearing in a given area (eg Savidge 1987; Woinarski et al. 2011). Actions may include specific experimental interventions to determine the causal processes underlying the decline that then help target actions (Runge et al. 2011).

Integrating monitoring and management planning and management intervention is clearly within the realm of strategic adaptive management (sensu Walters 1986), where adaptive management is "learning by doing", with the aim of combining the need for immediate action with a plan for learning (van Wilgen and Biggs 2011). Adaptive management has been widely advocated largely because of the intuitive appeal of evidence-based systems for environmental and biodiversity management. A part of this approach can include changing the monitoring regime itself (ie adaptive monitoring; sensu Lindenmayer and Likens 2009), such as increasing the frequency of monitoring to more rigorously quantify changes as well as monitoring the effectiveness of interventions designed to prevent the decline or extinction of a species.

Despite the extensive literature on adaptive management, there are few, practical, on-the-ground examples of successful implementation in biodiversity conservation (Westgate et al. 2013). The approach is particularly difficult to implement for rare and/or imperiled species because limited numbers of individuals or small population sizes complicate establishing replicated experiments (although see Mackenzie and Keith 2009).

\section{Suggested strategies}

We have drawn attention to some of the many cases wherein a species was monitored passively until it suffered local, regional, or global extinction due to the absence of a preplanned intervention program (WebTable 1). This is not meant as a criticism of ecological or conservation monitoring per se, since these are critical for understanding the ecology of a species, determining its threat status, and evaluating conservation management options. However, our analysis indicates that many existing conservation monitoring programs are not as effective as they could be at collecting information and prompting relevant actions. The following section outlines five key recommendations for improving conservation monitoring. Furthermore, we suggest that initiatives like the widely adopted IUCN Red List (IUCN 2012) be modified so that conservation monitoring and species recovery programs include well-defined trigger points for management intervention and guidance on what those management actions should be.

\section{Recommendation 1: explicit articulation of monitoring objectives}

Most conservation monitoring programs do not include a plan for exactly how the monitoring information will be used (Wintle and Lindenmayer 2008). Monitoring 
should aim to resolve uncertainties about how potential management actions change the system (eg what is the effect of feral predator control on adult survival rates in a threatened small mammal population?). The use of monitoring in this context can be broadly thought of as "learning" and generally involves using monitoring data to update or compare competing models of cause and effect. For monitoring information to be useful in resolving uncertainty about the relative effectiveness of conservation actions, it is critical that the correct "state variable" (eg juvenile survival, total population size) is monitored. However, the most appropriate state variable to be monitored is not always obvious; for example, if the long-term persistence of a species is highly dependent on juvenile female survival, then focusing on total population size may be a relatively inefficient way to evaluate the effectiveness of a proposed management action that targets juvenile female survival. In such a case, it may be more effective to concentrate on estimating changes in juvenile female survival. While this may seem trivial, many monitoring programs focus on estimating total population size irrespective of the type of management actions being implemented. Establishing firm links between conservation objectives, testing hypotheses of cause and effect that relate to threats, mitigating actions, and determining the state variable that most directly indicates the performance of management will improve conservation monitoring.

The effective use of monitoring to trigger timely planned conservation actions is equally reliant on a clear specification of conservation management objectives and identification of thresholds of acceptable and unacceptable change. Such thresholds are a risk management approach that reflects stakeholder preference for levels of risk. Because change normally cannot be observed with perfect accuracy, risk preferences must consider both the estimated magnitude of a change and the certainty with which the change is estimated. For example, a 30\% decline in a population over 10 years may be considered acceptable under some circumstances if it was certain that the decline was truly only $30 \%$. Given estimation uncertainty, a best estimate of decline in abundance of $30 \%$ may mean that there is a $40 \%$ chance that the true decline is greater than $50 \%$. These kinds of calculations are important to predetermine trigger points and ensure they are planned for well in advance.

\section{Recommendation 2: trigger points}

Many of the examples in WebTable 1 lacked built-in trigger points to activate management intervention in response to observed population changes. This omission is common in plans designed to recover and conserve species. We examined Australian species recovery plans published for threatened or endangered mammals, reptiles, amphibians, fish, and invertebrates (WebTable 2); only five of 122 recovery plans for 191 listed species made reference to monitoring programs with defined trigger points for management intervention in the event of a collapse in population size or rapid reduction in range (WebTable 2). For one of the five recovery plans - that for the Christmas Island pipistrelle - the trigger point was verification of a substantial population decline, which resulted in a legislative decision to uplist the conservation status to critically endangered. However, that action had little effect, given that the species is now believed to be extinct (Martin et al. 2012).

Our assessment of the scientific literature indicates there are only a few examples in which biodiversity monitoring programs contain formal and well-articulated trigger points. One of the best-known is that for the northern spotted owl (Strix occidentalis caurina) in western North America (USFWS 2011; US DOI 2012). Though, even in this case, the recovery actions are relatively generic and "aspirational", without clearly specified trigger points such as an increase of $x \%$ in the amount of reserved forest or numbers of competing owl species controlled in the event of a $y \%$ reduction in the abundance of the northern spotted owl over $z$ years.

We are aware of cases where preemptive action was taken to support the conservation of a given species prior to major impacts arising from external threats. High-profile cases include the introduction of the northern quoll (Dasyurus hallucatus) to offshore islands before the imminent invasion of the cane toad (Bufo marinus) in northern Australia (Rankmore et al. 2008), and the translocation of the Puerto Rican parrot (Amazona vittata) and the black-footed ferret (Mustela nigripes) in response to the potential risks to remaining populations from hurricanes and disease, respectively (Lacy et al. 1989; Oakleaf et al. 1993). These actions arose from far-sighted risk assessments and were not in response to triggers for management intervention formally embedded within a monitoring program, management plan, or a species recovery program.

Some examples of trigger points include an a-priorinominated percentage decline in population, duration of population decline, loss of numbers of subpopulations, or reduction in the distribution of a species (eg Figure 4). Identification of optimal trigger points could be achieved in a particular context, given more detailed knowledge about the costs, plausibility, and expected benefits of particular intervention actions (eg McDonald-Madden et al. 2010).

\section{Recommendation 3: plans for management action when trigger points are passed}

Trigger points must be accompanied by plans for the management actions that will be initiated, such as the removal of a proportion of the remaining population into captivity, the translocation of animals to other (nondeclining) subpopulations, or a concerted effort to address key threats, if known. The appropriate responses 


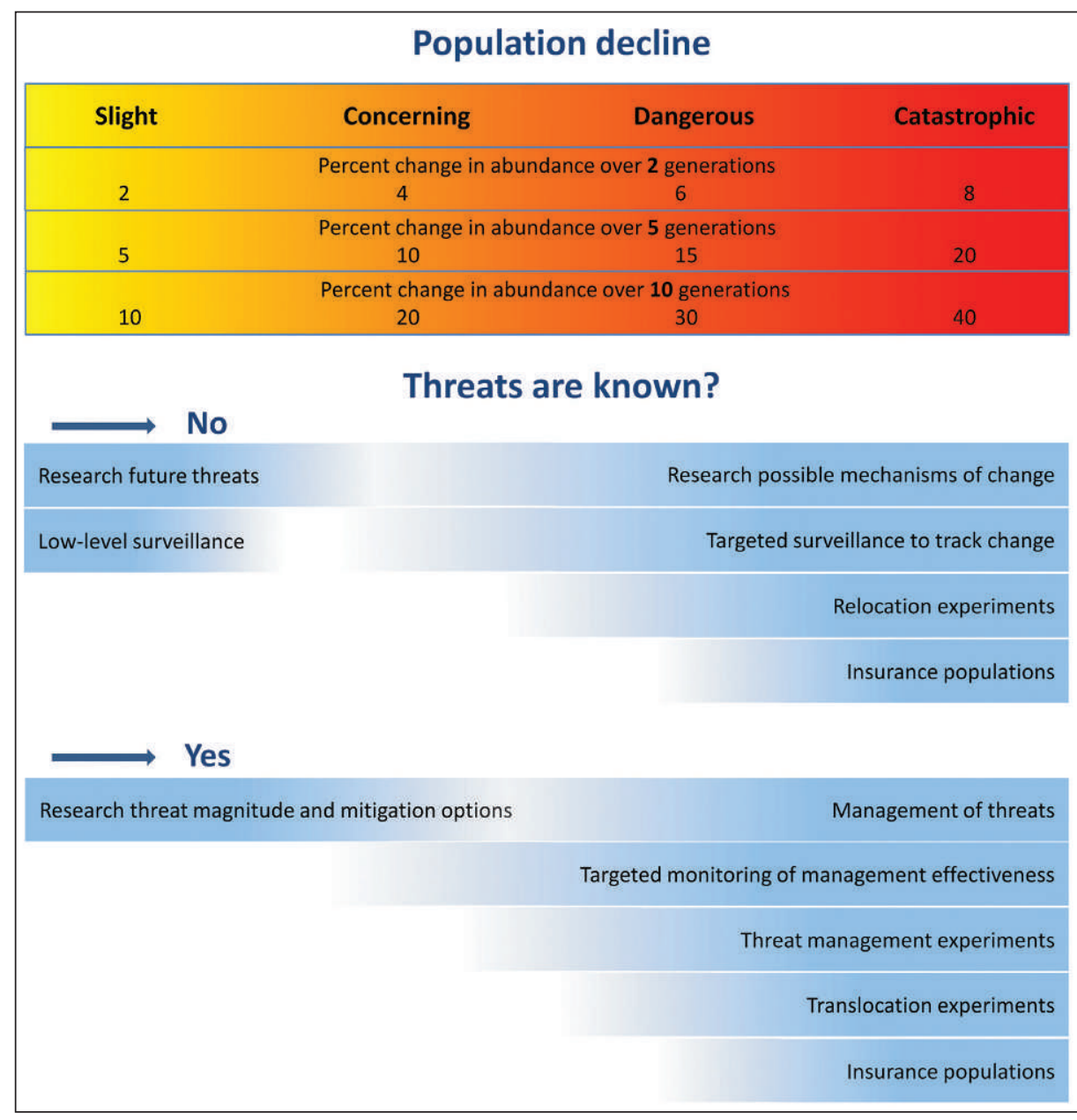

Figure 4. Planning a response to monitoring. The length of the blue bars indicates the range of declines over which a particular management response might be appropriate, including seeking more information through research, targeted monitoring, or surveillance monitoring. The percent population declines (red panels) provide an indication of the levels of decline that would trigger particular actions (blue panels).

to an observed population decline depend on the magnitude of the decline, the time period over which the decline was observed, whether the cause is well understood, the plausibility and cost of response actions, the size of the remaining population, and the need for further information. This range of factors means that it is not possible to identify a universally applicable set of actions that are most appropriate at particular levels of observed population decline. Nonetheless, it should be possible to identify a range of responses (Figure 4, blue panels) to observed declines (Figure 4, red panels) that may be appropriate given a particular context. The indicative percentages shown in Figure 4 are based on our experience with declining and/or threatened species as well as designing monitoring programs and do not represent optimized trigger points.

\section{Recommendation 4: power to detect change}

The statistical power of a monitoring program is loosely defined as the probability that a change of a given magni- tude will be detected if it occurs. Sufficient power to detect change lies at the heart of effective conservation monitoring programs (Nichols and Williams 2006). Statistical power in monitoring is influenced by the number, intensity, and frequency of field samples; the area covered by surveys; the level of change that needs to be detected; and the natural temporal fluctuations in population size.

The results of statistical power analyses should be published as part of the documentation for conservation monitoring programs. This may help to identify when and how such programs need to be modified to ensure that changes of concern do not go unnoticed and unmanaged.

\section{Recommendation 5: developing mechanisms for learning}

It is critical that lessons be taken from past experiences of extinction of monitored species. Frequent publication of monitoring outcomes and species recovery efforts would provide a sound basis for action and learning. This should include documentation of failures, as these often provide important suggestions for improvement (Redford and Taber 2000). For every species that goes extinct, we also recommend publishing a "why it went extinct obituary", which could be updated and published every few years as part of the IUCN Red List.

\section{Caveats}

A key problem with the application of trigger-based conservation monitoring programs that are linked with management plans is that monitoring can be expensive. Indeed, such programs are often the last item funded in a budget and the first to be cut when financial constraints are imposed (Wintle and Lindenmayer 2008). We argue that the conservation community must: (1) advocate vigorously for appropriate funding for welldesigned monitoring programs with high levels of statistical power to be embedded within conservation plans and to include clearly stated objectives, and (2) develop more cost-effective strategies for conservation monitoring programs, such as using rotating sampling methods 
(Welsh et al. 2000) and increasing reliance on citizen scientists to aid in collecting high-quality empirical data (Gardiner et al. 2012).

Finally, we recognize that even when effective monitoring and management are present and the drivers of decline have been identified, barriers such as lack of funding, stakeholder conflict, and cultural issues can thwart attempts to conserve particular species under threat (eg Rabinowitz 1995).

\section{Acknowledgements}

We thank many colleagues, including: $F$ Bunnell, P Burton, C Dickman, R Didham, P Ehrlich, A Felton, J Franklin, T Gardner, S Garnett, C Groves, R Hobbs, M Hunter, C Krebs, G Likens, B Laurance, S McIntyre, H Possingham, R Primack, R Noss, M Scott, T Spies, B Sutherland, D Wilcove, and J Wiens. C MacGregor manages the long-term field monitoring at Booderee National Park, southeastern Australia. DBL is supported by an ARC Laureate Fellowship, BAW is supported by an ARC Future Fellowship, and MPP is supported by an ARC DECRA. BAW and DBL are also supported by the Australian National Environmental Research Program.

\section{References}

Butchart SHM, Walpole M, Collen B, et al. 2010. Global biodiversity: indicators of recent declines. Science 32: 1164-68.

Caughley GC and Gunn A. 1996. Conservation biology in theory and practice. Cambridge, MA: Blackwell Science.

Dexter N, Ramsay DSL, MacGregor C, et al. 2012. Predicting ecosystem wide impacts of wallaby management using a fuzzy cognitive map. Ecosystems 15: 1363-79.

Director of National Parks. 2011. Booderee National Park draft management plan 2011-2021. Canberra, Australia: Director of National Parks.

Gardiner MM, Allee LL, Brown PM, et al. 2012. Lessons from lady beetles: accuracy of monitoring data from US and UK citizenscience programs. Front Ecol Environ 10: 471-76.

IUCN (International Union for Conservation of Nature). 2012. IUCN Red List of threatened species. Gland, Switzerland: IUCN.

Lacy RC, Flesness NR, and Seal US. 1989. Puerto Rican parrot population viability analysis. Report to the US Fish and Wildlife Service. Apple Valley, MI: Captive Breeding Specialist Group, Species Survival Commission, IUCN.

Lindenmayer DB. 2002. Gliders of Australia: a natural history. Sydney, Australia: UNSW Press.

Lindenmayer DB and Likens GE. 2009. Adaptive monitoring: a new paradigm in long-term studies. Trends Ecol Evol 24: 482-86.

Lindenmayer DB and Likens GE. 2010. Effective ecological monitoring. Melbourne, Australia, and London, UK: CSIRO Publishing and Earthscan.

Lindenmayer DB, MacGregor C, Welsh AW, et al. 2008. Contrasting mammal responses to vegetation type and fire. Wildlife Res 35: 395-408.

Mackenzie BDE and Keith DA. 2009. Adaptive management in practice: conservation of a threatened plant population. Ecol Manag Restor 10: 129-35.

Martin TG, Nally S, Burbidge AA, et al. 2012. Acting fast helps avoid extinction. Conserv Lett 5: 274-80.

McDonald-Madden E, Probert W, Hauser C, et al. 2010. Active adaptive conservation of threatened species in the face of uncertainty. Ecol Appl 20: 1476-89.

Nichols JD and Williams BK. 2006. Monitoring for conservation. Trends Ecol Evol 21: 668-73.

Oakleaf B, Luce B, Thorne ET, et al. 1993. Black-footed ferret reintroduction in Shirley Basin. 1992 Completion Report. Cheyene, WY: Wyoming Game and Fish Department.

Rabinowitz A. 1995. Helping a species go extinct: the Sumatran rhino in Borneo. Conserv Biol 9: 482-88.

Rankmore BR, Griffiths AD, Woinarski JCZ, et al. 2008. Island translocation of the northern quoll Dasyurus hallucatus as a conservation response to the spread of the cane toad Chaunus (Bufo) marinus in the Northern Territory, Australia. Palmerston, Australia: Department of Natural Resources, Environment and the Arts.

Redford $\mathrm{KH}$ and Taber A. 2000. Writing the wrongs: developing a safe-fail culture in conservation. Conserv Biol 14: 1567-68.

Runge MC, Converse SJ, and Lyon JE. 2011. Which uncertainty? Using expert elicitation and expected value of information to design an adaptive program. Biol Conserv 144: 1214-23.

Savidge JA. 1987. Extinction of an island forest avifauna by an introduced snake. Ecology 68: 660-68.

Soderquist TR, Lowe KW, Loyn RH, et al. 2002. Habitat quality in powerful owl (Ninox strenua) territories in the Box-Ironbark forest of Victoria, Australia. In: Newton I, Kavanagh RP, Olsen J, et al. (Eds). Ecology and conservation of owls. Melbourne, Australia: CSIRO Publishing.

Thomas JA, Simcox DJ, and Clarke RT. 2009. Successful conservation of a threatened Maculinea butterfly. Science 325: 80-83.

US DOI (US Department of the Interior). 2012. Endangered and threatened wildlife and plants; designation of revised critical habitat for the northern spotted owl. Federal Register 77; www.gpo.gov/fdsys/pkg/FR-2012-12-04/pdf/2012-28714.pdf. Viewed 3 Sep 2013.

USFWS (US Fish and Wildlife Service). 2011. Revised recovery plan for the northern spotted owl (Strix occidentalis caurina). Portland, OR: USFWS.

van Wilgen BW and Biggs HC. 2011. A critical assessment of adaptive ecosystem management in a large savanna protected area in South Africa. Biol Conserv 144: 1179-87.

Walters C. 1986. Adaptive management of renewable resources. New York, NY: Macmillan Publishing Company.

Welsh AH, Cunningham RB, and Chambers RL. 2000. Methodology for estimating the abundance of rare animals: seabird nesting on North East Herald Cay. Biometrics 56: 22-30.

Westgate MJ, Likens GE, and Lindenmayer DB. 2013. Adaptive management of biological systems: a review. Biol Conserv 158: 128-39.

Wintle BA and Lindenmayer DB. 2008. Adaptive risk management for certifiably sustainable forest management. Forest Ecol Manag 256: 1311-19.

Woinarski JCZ, Legge S, Fitzsimons JA, et al. 2011. The disappearing mammal fauna of northern Australia: context, cause and response. Conserv Lett 4: 192-201.

Yoccoz NG, Nichols JD, and Boulinier T. 2001. Monitoring of biological diversity in space and time. Trends Ecol Evol 16: 446-53. 